\title{
O processo de ensino-aprendizagem de Ciências em turmas com alunos deficientes visuais: percepções de professores
}

\author{
Iohanna Elizabeth Beckers* \\ Josefa Lídia Costa Pereira** \\ Anderson Giovani Trogello***
}

\section{Resumo}

O ensino de astronomia voltado para alunos com necessidades educacionais especiais deve acontecer de forma a envolver de modo inclusivo o participante no processo de ensino aprendizagem. Dessa forma, alunos com deficiência visual necessitam de ações que privilegiem os diversos sentidos, exceto a visão. Assim, o presente trabalho se dispôs a entrevistar professores de séries iniciais do ensino fundamental, objetivando analisar como acontece o processo de ensino aprendizagem dos conteúdos astronômicos em turmas que possuem alunos deficientes visuais inclusos. Tais análises demonstraram que o ensino de astronomia praticado pelos professores privilegiou uma linguagem áudio visual, o que pode desfavorecer a participação dos deficientes visuais.

Palavras-chaves: Ensino de Astronomia; Deficiente Visual; Metodologias de ensino.

* Graduanda em Educação Especial pela Universidade Federal de Santa Maria, modalidade a distância, polo Darci Ribeiro, Foz do Iguaçu, Paraná, Brasil.

** Professora Doutora do Departamento de Educação Especial na Universidade Federal de Santa Maria, Santa Maria, Rio Grande do Sul, Brasil.

*** Servidor Estadual da Educação Basica e cursa a Especialização de nível Mestrado em Ensino de Ciências e Tecnologia na Universidade Tecnológica Federal do Paraná. Ponta Grossa, Paraná, Brasil. 


\section{The process of teaching and learning in classes with visual deficient students: perceptions of teachers}

\section{Abstract}

The teaching of astronomy focused on students with special educational needs must happen in order to involve the participant so inclusive in the process of teaching and learning. Thus, students with visual deficient require actions that favor the different senses but sight. Thus, this study set out to interview teachers in early grades of elementary school, aiming to analyze how the process of teaching and learning of astronomical content in classrooms that have included visual deficient students happens. Such analysis showed that the teaching of astronomy practiced by teachers favored an audio-visual language. It may discourage the participation of the visual deficient ones.

Keywords: Teaching of Astronomy; Visual Deficient; Teaching methodologies.

\section{Introdução}

O ambiente escolar organizado em currículos disciplinares visa a contribuir para que os alunos construam conhecimentos necessários a uma atuação efetiva junto à sociedade (SAVIANI, 1994; PARANÁ, 2008). Dessa forma, é essencial que os alunos tenham acesso a todos os currículos durante seu processo educativo (LUNARDI, 2005).

Quando é dito "para todos", entende-se que a educação deve envolver todos os alunos na sua diversidade. Nessa premissa, são direcionados os preceitos de uma Educação Inclusiva, os quais são verificáveis na Declaração de Salamanca de 1994, que argumenta que a pessoa com necessidades educacionais especiais deve receber a mesma educação sem distinção em relação as suas limitações (BRASIL, 1994). Tais preceitos são encontrados também na Lei de Diretrizes e Bases 9.394, do ano de 1996, que assegura à criança com deficiência física, sensorial e mental o direito de estudar em classes comuns, ou seja, preferencialmente na rede regular de ensino, garantindo que as necessidades específicas dos alunos sejam supridas (BRASIL, 1996; BRASIL, 2006).

Nesse sentido, Munhóz (2005) argumenta que uma educação pautada nos objetivos da teoria de aprendizagem sócio-interacionista deve considerar como influência principal na aprendizagem, a relação do aluno com o meio e não os fatores psíquicos e físicos. Para a autora, o meio social pode facilitar ou dificultar a aquisição da aprendizagem e desenvolvimento, uma vez que as dificuldades relevadas por uma pessoa com necessidades especiais podem ser decorrentes muito mais da falta de interação social, do que de sua condição orgânica limitada. Assim, pode-se inferir que 
a educação de crianças com necessidades especiais necessita estar atenta para valorizar a busca de caminhos para superação das dificuldades apresentadas por essas pessoas. O ensino deve objetivar a valorização da qualidade da interação dos sujeitos com seus pares, e não as limitações de cada pessoa.

Cada disciplina do currículo escolar irá prover informações necessárias ao indivíduo para a construção de conhecimentos. Assim em Brasil (1998), o Ensino de ciências é encarregado de um papel fundamental, o de promover o debate e a investigação visando ao entendimento da ciência como construção histórica e saber prático. Para Pinheiro, Silveira e Bazzo (2007), a educação em ciências é necessária para o aluno compreender as ações científicas e tecnológicas em meio ao cenário atual, além de perceber que o desenvolvimento científico é um processo inacabado, que não é avesso às vontades mundanas.

De um modo geral, o processo de ensino de ciências deve prover embasamentos para que o indivíduo possa compreender os fenômenos que acontecem ao seu redor e, dessa forma, possa interagir e contribuir na sociedade, participando criticamente dos debates contemporâneos como clonagem, tecnologia, aborto, injustiças ambientais, aquecimento global, exploração espacial, etc. (LORENZETTI; DELIZOICOV, 2001; BRASIL, 2006).

Correlato a tal discurso, tem-se o ensino de conteúdos astronômicos, os quais despertam curiosidade e fascínio por parte dos estudantes (PEDROCHI; NEVES, 2005). Parte integrante do ensino de ciências, o ensino de Astronomia engloba conceitos que vêm a auxiliar o indivíduo no entendimento de seu meio, o que possibilita a compreensão de conceitos como mudanças sazonais, características do universo, do sistema solar, efeito da radiação solar nas ferramentas e no corpo humano, localização espacial, entre outros (PARANÁ, 2008). Dessa forma, é fundamental que conceitos astronômicos sejam trabalhados já nas séries iniciais do Ensino Fundamental e que todos os alunos tenham acesso a tais conteúdos (BRASIL, 2006; PARANÁ, 2008).

Entretanto, o ensino de Astronomia encontra-se deixado de lado nos currículos de ciências e, quando trabalhado em sala de aula, não valoriza o cotidiano dos alunos e não transpõe as abstrações dos fenômenos celestes. O ensino de Astronomia está pautado na exposição de conteúdos e na linguagem audiovisual. Nesse sentido, tal tarefa necessita de intervenções que agucem a curiosidade dos alunos e, sobretudo, tornem o fenômeno astronômico palpável, transpondo as abstrações dos alunos (PEDROCHI; NEVES, 2005).

Essa situação também acontece com o ensino de Astronomia disponibilizado aos alunos deficientes visuais. O mais preocupante é que esses não são favorecidos pela linguagem visual. Dessa forma, o presente trabalho vem abordar especificamente o tema da deficiência visual, o que é aqui compreendida como a situação de cegueira ou baixa visão. Assim, pessoas cegas são aquelas que "apresentam desde ausência total de visão até a perda da projeção de luz" (BRUNO; MOTA, 2001, p. 35). 
Já, as pessoas com baixa visão são "aquelas que apresentam desde condições de indicar projeção de luz até o grau em que a redução da acuidade visual interfere ou limita seu desempenho" (BRUNO; MOTA, 2001, p. 34). Para essas pessoas, o processo de ensino aprendizagem não deve estar pautado no visual. Cabe ao professor a análise, a organização e a sistematização de atividades pedagógicas específicas, necessárias ao desenvolvimento integral do aluno deficiente visual, como também é função do educador propor e adaptar atividades lúdicas, prazerosas e situações de interação, socialização e participação coletiva com os demais alunos.

Entretanto, a ação docente destinada a alunos com deficiência visual desfavorece a inclusão desses alunos, como é averiguado no trabalho desenvolvido por Costa, Neves e Barone (2006), no qual destaca-se que o ensino de Ciências naturais para pessoas com deficiência visual está marcado por uma série de contingências que comprometem a inclusão na escola regular. Os autores relatam que essa situação ocorre devido a falta de recursos didáticos adequados, à exclusão tecnológica, à ausência da experimentação na escolarização do deficiente visual, à didática baseada exclusivamente no visual, à evasão escolar, ao despreparo docente para o ensino dos deficientes visuais e a falta de pesquisas sobre este tema.

E Masini (1990), em estudo com professores e especialistas, diz que o ensino direcionado para os alunos com deficiência visual tem como pressuposto os padrões adotados para os videntes. Ou seja, valoriza o "ver" e, portanto, não levam em conta as diferenças entre o deficiente visual e o vidente.

Já, no trabalho de Camargo, Nardi e Sparvoli (2010) é observado que os professores da disciplina de física do ensino médio se utilizam de uma linguagem que pouco favorece a aprendizagem dos alunos com deficiência visual.

Nesse sentido, são de fundamental importância trabalhos que abordem o ensino de Astronomia para alunos deficientes visuais. Assim, a presente pesquisa intensificou seus esforços a compreender a ação docente em séries iniciais com tais conteúdos em turmas que possuam alunos deficientes visuais incluídos. Mais precisamente, esse trabalho procurou levantar as de um grupo de professores da educação básica, arrolando-as em relação à abordagem metodológica e ao emprego de objetos adaptados. E, adjacente, averiguou as possíveis barreiras existentes durante o processo de ensino e aprendizagem no referido contexto.

\section{Metodologia da pesquisa}

A presente pesquisa, caracterizada como qualitativa, visou avaliar as representações do trabalho docente em turmas do ensino fundamental (série iniciais) com alunos deficientes visuais incluídos. Como afirma Patton (1986), a pesquisa qualitativa descreve as relações entre a fala e suas experiências. E, para isso, é necessário que o pesquisador esteja munido de uma visão holística, de uma abordagem indutiva e de uma investigação naturalística, pois, o discurso representado, neste caso pelos professores, não pode ser entendido de forma descontextualizada. 
Assim, as falas de cada docente analisadas aqui, são entendidas como discurso, o qual é interpretado em Orlandi (2005) como componente da condição humana, pois é com ele que o indivíduo interage na sociedade. Ele é formado de acordo com as concepções, as crenças, a cultura, as aflições e os desejos da pessoa. Assim, a constituição do discurso é dependente da vivência, da história, da ideologia do ser humano.

Foram analisados os discursos de quatro professoras das redes municipais de ensino dos municípios de Itaipulândia e Missal, ambos localizados na região oeste do estado paranaense. O reduzido número é justificado pela redução de custos do projeto; pelos municípios possuírem poucas turmas com deficientes visuais inclusos e pela resistência de alguns professores em pesquisas que avaliem seu trabalho em sala de aula (por mais que a proteção de suas identidades fosse garantida).

Para se chegar ao número de quatro professoras, primeiramente, foi realizado um levantamento de alunos deficientes visuais inclusos no ensino fundamental (séries iniciais) junto às secretarias de educação dos referidos municípios. É importante salientar que por se tratar de uma pesquisa qualitativa, este projeto não objetiva traçar um panorama geral de como é trabalhado os conteúdos de Astronomia em salas com alunos cegos e baixa visão, mas sim almeja averiguar (nos casos avaliados) as concepções e ações desenvolvidas por aqueles professores. Deste modo, espera-se que os estudos destes casos, possam contribuir para futuras intervenções docentes, em salas, com alunos não visuais, além de geometrizar o trabalho no âmbito regional. Reforçando, assim, intervenções como a desta pesquisa em outras localidades.

A coleta de dados foi encaminhada por meio de uma entrevista semiestruturada, na qual a pesquisadora se utilizou de um questionário previamente elaborado. Esta metodologia tem a finalidade de dinamizar, manter o foco durante as entrevistas e recolher uma maior quantidade de dados. Também, com a mesma finalidade, foi utilizado, com autorização prévia das participantes um aparelho de gravação de voz. Tais entrevistas aconteceram durante o segundo semestre de 2011. Ainda, nesse período, decorreu a avaliação dos discursos (ORLANDI, 2005).

É importante salientar que este trabalho contou com a colaboração do órgão fomentador PTI (Polo Tecnológico da Itaipu), das secretarias educacionais dos municípios supracitados e dos órgãos de ensino UAB (Universidade Aberta do Brasil - Campus de Foz do Iguaçu - PR) e da UFSM (Universidade Federal de Santa Maria - RS).

\section{Resultados e discussões}

Das quatro entrevistadas, apenas uma atuava no município de Itaipulândia e as outras atuavam no município de Missal. E, para critérios de organização e localização durante o texto, as professoras serão chamadas por ordem de entrevista, de Pl, P2, P3 e P4. 
Inicialmente, a entrevista se direcionou por perguntas sobre a formação acadêmica, formação continuada e/ou complementar na área de deficiência visual e experiência como docente. Tais questionamentos revelaram que as professoras possuíam formação em Pedagogia. As entrevistadas Pl, P2 e P3 declararam formação continuada com especialização em educação especial, sendo que as entrevistadas P2 e P3 apresentaram formação complementar em Braille. Com relação ao tempo de experiência docente, as entrevistadas relataram: Pl, 17 anos; $\mathrm{P} 2,12$ anos; $\mathrm{P} 3,21$ anos, e P4, 11 anos.

De acordo com as respostas, é tácito inferir que os professores possuíam formação adequada para o trabalho com educação básica, bem como para a educação inclusiva. Conforme Gatti (2009), os currículos dos cursos de Pedagogia abordam o tema Educação Especial. Entretanto, como salienta Paro (2001), em relação ao processo educativo, uma coisa é falar do que poderia ser, outra coisa bem diferente é verificar se o que é considerado está sendo cumprido. Gatti (2009) complementa que os conteúdos específicos das disciplinas a serem ministradas em sala de aula, como é o caso do ensino de ciências, não são objeto dos cursos de pedagogia.

Ainda, com base nos dizeres de Gatti (2009), os cursos de Pedagogia acionam uma referência de alerta, quando os assuntos são os conteúdos da disciplina de ciências. Para a autora, tais conteúdos aparecem apenas esporadicamente nos cursos de Pedagogia, ou ainda, são abordados de forma genérica ou superficial no interior das disciplinas de metodologias e práticas de ensino. Esta graduação não pode ser compreendida como garantia de cumprimento das funções docentes, em especial com relação às atividades referentes ao ensino de conteúdos científicos e à educação inclusiva.

Dessa forma, é congruente dizer que o suporte à formação docente está na formação continuada. Como afirma Sant'Ana (2005), aparentemente a formação continuada favorece a implementação da proposta inclusiva. Entretanto necessita estar aliada a melhorias nas condições de ensino, bem como ao suporte de profissionais no auxílio ao trabalho do professor e ao compromisso de cada profissional em trabalhar para a concretização dessas mudanças.

Conseguintemente, pode-se dizer que as especializações em Educação Especial contribuem em muito para a atividade com alunos incluídos. Entretanto, de uma forma generalizada, faltam cursos de pós-graduações referentes ao ensino de Astronomia (BARROS, 1997; PEDROCHI, NEVES, 2005). Tais cursos também não foram oportunizados aos professores participantes desse estudo (quadro 1). Ainda como salienta Sant'Ana (2005), a formação docente não pode restringir-se à participação em cursos eventuais, mas sim, em cursos que sejam realizados de forma integrada e permanente. 


\begin{tabular}{|c|c|c|c|c|}
\hline Professor & $\begin{array}{c}\text { Formação Acadê- } \\
\text { mica }\end{array}$ & $\begin{array}{c}\text { Formação } \\
\text { Continuada }\end{array}$ & $\begin{array}{c}\text { Formação } \\
\text { Complementar }\end{array}$ & $\begin{array}{c}\text { Tempo de } \\
\text { serviço como } \\
\text { professora }\end{array}$ \\
\hline P1 & Lic. Plena Pedagogia & $\begin{array}{c}\text { Especialização } \\
\text { Educ. Especial }\end{array}$ & Não possui & 17 anos \\
\hline P2 & Lic. Plena Pedagogia & $\begin{array}{c}\text { Especialização } \\
\text { Educ. Especial }\end{array}$ & Curso de Braile & 12 anos \\
\hline P3 & Lic. Plena Pedagogia & $\begin{array}{c}\text { Especialização } \\
\text { Educ. Especial }\end{array}$ & Curso de Braile & 21 anos \\
\hline P4 & Lic. Plena Pedagogia & Não possui & Não possui & 11 anos \\
\hline
\end{tabular}

Quadro 1: Relação dos professores, formação acadêmica, formação continuada, formação complementar e tempo de serviço como docente.

Outro dado relevante é que os professores entrevistados possuíam entre ll e 21 anos de tempo de serviço como docente. Essa situação é amplamente analisada em Tardif e Raymond (2000), para eles em termos sociológicos, o trabalho modifica a identidade do trabalhador, pois trabalhar não é somente fazer alguma coisa, mas fazer alguma coisa de si mesmo. O trabalhador se perfaz em sua prática. Ao analisar especificamente o oficio magistério, os autores salientam, embasados em Schwartz (1997), que um professor, ao longo de sua carreira, não faz simplesmente alguma coisa, ela faz também alguma coisa de si mesmo: sua identidade carrega as marcas de sua própria atividade, e uma boa parte de sua existência é caracterizada por sua atuação profissional. Assim, com o passar do tempo, o educador se complementa com os saberes, complementa sua própria prática e passa a inferir em sua ação com sua cultura, seu éthos, suas ideias, suas funções, seus interesses etc.

Ainda com Tardif e Raymond (2000), os educadores possuem saberes fundamentais a sua prática, tais como: saber pessoal dos professores, arraigados à vivência primeira junto aos familiares e à educação lato sensu; Saberes provenientes da formação escolar anterior, aquela proveniente da educação básica; Saberes provenientes da formação profissional para o magistério, oriundos da formação acadêmica de professores, dos estágios, cursos de reciclagem e formação continuada; Saberes provenientes dos programas e livros didáticos usados no trabalho, tais materiais representam fundamentação de auxilio aos professores, os quais embasam a ação docente; e, por fim, se têm os Saberes provenientes de sua própria experiência na profissão, uma vez que os professores arraigam atributos da relação com os pares, durante sua profissão. Dessa forma, pensar a ação docente de forma completa é conciliar todos os tipos de saberes e não apenas a formação acadêmica e continuada. É tácito que tais saberes são fundamentais ao processo de constituição de docentes, entretanto esta tem de ser completada com uma formação prática, isto é, com uma experiência direta do trabalho.

Assim é possível inferir que os profissionais entrevistados compactuam de uma larga experiência docente favorável às multiplicidades constituídas em sala de aula. Ainda, tal situação corresponde a mencionar que a inclusão de alunos com deficiência em turmas regidas por professores com enfática experiência docente contribua para uma regência mais esclarecida e preparada para a diversidade. 
Na sequência, foi averiguado o número de alunos presentes nas turmas que possuíam alunos incluídos por deficiência visual. Tal configuração é demonstrada abaixo no quadro 2 .

\begin{tabular}{|c|c|c|c|}
\hline Professor & Série & Número de alunos & $\begin{array}{c}\text { Alunos com } \\
\text { deficiência visual }\end{array}$ \\
\hline P1 & $5^{\text {o }}$ Ano & 24 & 1 \\
\hline P2 & $3^{\text {o Ano }}$ & 17 & 1 \\
\hline P3 & $5^{\text {}}$ Ano & 22 & 1 \\
\hline P4 & $2^{\text {o Ano }}$ & 21 & 2 \\
\hline
\end{tabular}

Quadro 2: Relação das turmas que possuem aluno(s) com deficiência visual.

Com relação ao tamanho da turma, Waiselfisz (2000) remete à concepção por vezes alternativa e incipiente, de que quanto menor for o número de alunos em uma turma, maior será a aprendizagem, pois, dessa forma, são creditadas ao professor melhores condições para se dedicar e acompanhar individualmente seus alunos, flexibilizando suas estratégias e ritmos de acordo com as necessidades individuais, e ampliando, dessa forma, o leque de possibilidades e oportunidades educacionais para os educandos. Entretanto, como destaca o autor, a redução do número de alunos por turma implicaria limitações quanto às despesas orçamentárias.

Para Naujorks (2002), uma série de fatores podem representar situações estressantes aos professores, frente à inclusão de alunos com necessidades especiais, dentre as quais são destacadas: falta de preparo dos professores; infraestrutura física inadequada; pouco apoio pedagógico para trabalhos em equipe; o desinteresse da família para o processo educativo de seus filhos; indisciplina escolar; desvalorização da função docente, e o número elevado de alunos por turmas.

De fato, existe a preocupação do número de alunos por turma para o processo de ensino e aprendizagem. Como menciona Waiselfisz (2000), há estudos que apontam para um número ideal de no máximo 15 (quinze) a 20 (vinte) alunos por turma. Entretanto, o autor admite (ao avaliar testes e o referido número de alunos por turma) não ter encontrado diferença significativa que confirme a relação de melhoria da aprendizagem ao reduzir o número de alunos. Para o autor, a variação na aprendizagem está relacionada a fatores como a formação de professores e principalmente as técnicas de ensino que tais professores utilizam em sala de aula.

Nesse sentido, a ação docente necessita de constantes inferências e reformulações quanto a suas práticas e seus discursos (LABURÚ, ARRUDA, NARDI, 2003; ZANELLA, 2003; KRASILCHICK, 2005). Costa, Neves e Barone (2006) destacam que um ensino eficiente para turmas com alunos inclusos com deficiência visual necessita de professores habilitados, instrumentos e objetos didáticos que auxiliem a participação dos alunos, a fim de ultrapassar o ensino tradicional que pouco contribui para o processo de ensino aprendizagem e, em especial, pouco contribui para o trabalho de conteúdos como o de astronomia com alunos com deficiência visual. 
Ainda, objetivando traçar a realidade na qual se encontram essas turmas, os participantes foram questionados quanto à presença de um profissional auxiliar, atuando com os alunos deficientes visuais no decorrer do período letivo. Assim, foi constatada a presença de tal profissional apenas com P4. Entretanto, a professora P3 afirmou "No início do ano, sim, porém depois passou a ser função da professora regente (no caso ela própria)". Como mencionam Costa, Neves e Barone (2006), a falta de monitoria adequada aos deficientes visuais acarreta perdas ao processo de ensino e aprendizagem.

É valido ressaltar que ambas as secretarias de educação dos municípios alvos deste trabalho, possuem uma profissional com formação continuada em Educação Especial que presta suporte às turmas em processo de inclusão. O conhecimento da função dessa profissional ficou evidente nas respostas de P2, P3 e P4. Como salienta P3: "Sim, há a visita periódica da professora especialista do CAE-DV (Centro de Assistência Especializado - Deficiente Visual) na escola”. A presença de tal profissional é essencial ao processo educacional de turmas com deficientes visuais, como salientam Maciel (2000) e Sant'Ana (2005). Entretanto, a profissional Pl argumentou que não existia profissional do município, demonstrando desconhecimento quanto aos serviços oferecidos e realizados pela secretaria de educação.

$\mathrm{Na}$ sequência, os professores foram questionados sobre o trabalho com os conteúdos de Astronomia. Primeiramente, foi perguntado quanto às metodologias utilizadas e, em seguida, sobre os materiais didáticos usados em sala de aula. A professora Pl disse: "Passei vários vídeos, utilizei o planetário, levei as crianças ao pátio para observar a sombra para compreenderem os movimentos da Terra". A professora P2 comentou que atuou através de aulas expositivas e demonstrações, nas quais utilizou materiais como globo terrestre e o planetário. Já, a professora P3 argumentou que este conteúdo era trabalhado de maneira expositiva, ela informou não possuir, na escola, materiais didáticos para o trabalho nas aulas. E a P4 relatou que o currículo de ciências de sua turma não contempla enfaticamente os conteúdos astronômicos, entretanto, os poucos conteúdos, segundo ela, eram trabalhados de maneira expositiva.

As respostas das participantes revelam um ensino no visual e oral. Os verbos, "observar", "demonstrar" e "expor" (verbal) não valorizam a acuidade dos fenômenos por parte dos alunos deficientes visuais. Dessa forma, atividades como a visualização de vídeos podem excluir tais alunos de parte do processo, por estarem atreladas à linguagem áudio visuais. Como mencionam Costa, Neves e Barone (2006), o ensino de conteúdos físicos está arraigado ao processo visual. E tal característica não é modificada para os alunos que possuem deficiência visual. 


\begin{tabular}{|c|c|c|c|}
\hline Professor & $\begin{array}{c}\text { Qual metodologia } \\
\text { usou? }\end{array}$ & $\begin{array}{c}\text { Utilizou objetos } \\
\text { didáticos? }\end{array}$ & $\begin{array}{c}\text { Utilizou metodolo- } \\
\text { gia diferenciada aos } \\
\text { alunos deficientes } \\
\text { visuais? }\end{array}$ \\
\hline P1 & $\begin{array}{c}\text { Vídeos, Demons- } \\
\text { trações, Atividades } \\
\text { práticas. }\end{array}$ & Planetário, Gnômon. & Não utilizou \\
\hline P2 & $\begin{array}{c}\text { Aulas expositivas e } \\
\text { Demonstrações }\end{array}$ & $\begin{array}{c}\text { Planetário e Globo } \\
\text { Terrestre }\end{array}$ & Não utilizou \\
\hline P3 & Aula expositiva & Não utilizou & Não utilizou \\
\hline P4 & Aula expositiva & Não utilizou & Não utilizou \\
\hline
\end{tabular}

Quadro 3: Relação das técnicas utilizadas pelos professores nas aulas de astronomia.

O apelo visual também é uma das características de modelos didáticos. Atividades como a demonstração de globo terrestre, do planetário ou de gnômon (corpo posicionado perpendicular ao solo e exposto à luz solar) são atividades interessantes ao processo de ensino de Astronomia, pois favorecem a percepção visual dos alunos. Entretanto, eximem a participação de alunos com deficiência visual. Como mencionam Cerqueira e Ferreira (2000) e Brasil (2001), os recursos didáticos adaptados aos deficientes visuais são indispensáveis, pois motivam a participação dos alunos, suprem lacunas observacionais, possibilitam o treinamento tátil e a percepção de detalhes e posterior esquematização do fenômeno.

O processo de percepção tátil é utilizado como incentivo para o uso de modelos didáticos, modelos em alto relevo, com texturas, ou dimensionais, que possibilitam ao aluno deficiente visual a percepção do fenômeno (CERQUEIRA, FERREIRA, 2000; BRASIL, 2001; ALMEIDA, LOCH, 2005; LOCH, 2008). Tais considerações possibilitam inferir que as atividades propostas pelos professores não privilegiam a participação dos alunos com deficiência visual, pois tais atividades não estão atreladas a discriminações táteis e/ou impossibilitam a percepção dimensional do fenômeno. A ausência de aproximação do fenômeno físico, para o aluno deficiente visual, pode conduzir a aprendizagem ao mero verbalismo, desindexada de sua realidade (CERQUEIRA, FERREIRA, 2000; COSTA, NEVES, BARONE, 2006).

Quando questionadas sobre a produção de materiais didáticos, as entrevistadas P2, P3 e P4 argumentaram que não produziam materiais que pudessem ser utilizados no ensino de astronomia. Apenas a Pl relatou a confecção de modelo didático para a representação do sistema solar e das fases da lua. O "não fazer" dos professores remonta ao fato, anteriormente exposto, de que o ensino de astronomia das turmas ora estudadas é embasado no "ver", no "falar", e não no tocar. Mesmo a atividade proposta pela Pl configura tal situação, uma vez que também favorece a percepção visual do fenômeno, tal como o globo terrestre e o planetário. Como mencionam Cerqueira e Ferreira (2000), a produção de objetos de aprendizagem, voltados para o ensino com deficientes visuais, deve favorecer a percepção tátil. Tais objetos podem ser confeccionados com materiais de baixo custo, recicláveis e/ou presentes na natureza. Essas afirmativas podem ser vistas como incentivos à produção por parte dos educadores. 
Entretanto, não é isso que foi averiguado. Essa nova situação remonta, novamente, ao fato do despreparo do professor, ou seja, faltam oportunidades em cursos complementares de tais significados, conceitos e técnicas.

Entretanto, mesmo com a avaliação das falas dos professores revelando um ensino pautado no verbalismo e no visual, desfavorecendo assim a participação dos alunos com deficiência visual, o último questionamento demonstrou que todos os professores afirmaram não ter dificuldades com o trabalho de conteúdos de astronomia.

\section{Conclusão}

De acordo com o estudo realizado, observou-se, inicialmente, que as professoras apresentavam tempo de serviço considerável. Tal característica pode favorecer o trabalho docente, uma vez que a atividade profissional contribui para a formação do indivíduo (TARDIF, RAYMOND, 2000). Uma larga experiência docente se torna um trunfo às multiplicidades constituídas em sala de aula, favorecendo a inclusão.

Outro dado importante, aferido nas questões inicias, diz respeito a formação acadêmica e continuada das docentes. As participantes apresentaram formação acadêmica e continuada adequada ao processo de ensino e aprendizagem para alunos inclusos. Todas as entrevistadas mencionaram graduação em pedagogia e três arguiram ainda o título de especialista em educação especial. Aparentemente, esta situação pode ser correlacionada com uma docência esclarecida quanto a inclusão, inclusive de alunos não visuais. No entanto, de acordo com a bibliografia consultada evidencia-se em graduações do magistério precariedade quando o assunto é ensino de ciências (GATTI, 2009). Já nas especializações e cursos complementares, o que é observado é a falta de cursos de Astronomia (BARROS, 1997; PEDROCHI, NEVES, 2005).

Entretanto, o presente texto não se ateve a investigar especificamente os currículos das graduações e especializações apresentadas nas entrevistas. Além disso, trabalhos que envolvam a análise de tais grades quanto ao trabalho da inclusão de deficientes visuais, ou ainda, do envolvimento com conteúdos de Astronomia são escassos, mesmo atualmente. Desse modo, a sugestão ou mesmo o apelo para iniciativas que abordem estes temas são aguardadas.

O número de alunos por turma foi outra informação arrolada nas entrevistas. Embora sua relação com a aprendizagem, em virtude de alunos inclusos não tenha sido investigada abrindo margens para novos trabalhos, percebe-se, de acordo com a bibliografia abordada (WAISELFISZ, 2000; NAUJORKS, 2002), que a presença de poucos ou muitos alunos ainda não pode ser relacionada como critério para o processo de ensino e aprendizagem, devido, principalmente, a ausência de trabalhos que abordem tal tema. 
A falta de profissionais auxiliares atuando em sala de aula junto ao regente - especialmente em três casos, é outro fato de destaque. A presença de tal função é essencial ao processo educacional de turmas com deficientes visuais, o auxílio ao aluno pode favorecer o contato com a linguagem estipulada em sala de aula pelo regente.

Quanto as metodologias e objetos utilizados, averiguou-se em tais situações um ensino de Astronomia pautado no áudio visual, não utilizando instrumentos e atividades que auxiliassem o trabalho com deficientes visuais. Aulas demonstrativas e expositivas, com a utilização de vídeos e planetários, e/ou, visualizando a movimentação da sombra de um gnômon, são atividades arroladas pelas professoras daqueles munícipios que desfavorecem a aprendizagem de alunos não videntes.

Dessa forma, percebeu-se a exclusão dos alunos deficientes visuais durante o processo de ensino e aprendizagem de conceitos astronômicos, pois estes necessitavam de atividades diferenciadas, pautadas em sentidos avessos à visão, como modelos em dimensões apropriadas, com texturas, em alto-relevo, impressos em Sistema Braille. Tais adaptações não foram identificadas entre as ações dos docentes. Muito pelo contrário: atividades expositivas (oral - áudio) e demonstrações visuais se apresentavam de forma ambígua às ações dos docentes entrevistados.

A constatação da necessidade de cursos de cunho complementar para áreas das ciências naturais, objetivando ações mais esclarecidas com alunos deficientes visuais pode ser defendida por este trabalho. Bem como, é constatada a necessidade de trabalhos em diferentes frentes em relação ao trabalho inclusivo de deficientes visuais.

Compreender a necessidade e empreender uma abordagem diferenciada para aquele aluno incluído, talvez seja a maior dificuldade daquelas entrevistadas. Seja pela inexperiência com tal situação, ou pela defasagem de sua formação, ou ainda pela falta de materiais, instrumentos e apoio pedagógico, é certo que situações encontradas nesse grupo podem ser reeditadas em outros locais.

\section{Referências}

ALMEIDA, L. C.; LOCH, R. E. N. Mapa tátil: passaporte para a inclusão. Extensio - revista eletrônica de extensão, v. 2, n. 3, 2005. Disponívelem: 〈http://journal.ufsc.br/index.php/ extensio/article/view/5482/4915〉. Acesso em: 10 out. 2011.

BARROS, S. G. La Astronomía en textos escolares de educación primaria. Enseñanza de las Ciencias, v. 15, n. 2, p. 225-232, 1997.

BRUNO, M.M.G., MOTA, M.G.B. Programa de Capacitação de Recursos Humanos doEnsino Fundamental: deficiência visual. Brasília: Ministério da Educação, Secretaria de Educação Especial, v .l, fascículo I, 2001.

BRASIL. Declaração de Salamanca e linha de ação sobre as necessidades educativas especiais. CORDE. Brasília, DF, 1994. 
BRASIL. Ministério da educação, Secretaria de Educação Básica. Orientações curriculares para o ensino médio: Ciências da Natureza, matemática e suas tecnologias. Brasília, DF, 2006.

BRASIL. Secretaria de Educação Fundamental. Parâmetros Curriculares Nacionais. Ciências Naturais/ Secretaria de Educação Fundamental. Brasília, DF, MEC/SEF, 1998.

BRASIL. Lei de Diretrizes e Bases da Educação da Educação Nacional. Brasília, DF, 1996.

CAMARGO, E. P.; NARDI, R.; SPARVOLI, D. P. Contextos comunicacionais adequados e inadequados à inclusão de alunos com deficiência visual em aulas de termologia. Revista de Enseñanza de la Física. v. 23, n. 1 y $2,2010$.

CERQUEIRA, J. B.; FERREIRA, M. A. Os recursos didáticos na educação especial. Revista Benjamin Constant, v. 15, Rio de Janeiro, RJ, 2000.

CHASSOT, A. Alfabetização científica: uma possibilidade para a inclusão social. Revista Brasileira de Educação, n. 22, 2003.

COSTA, L. G.; NEVES, M. C. D.; BARONE, D. A. C. O ensino de Física para deficientes visuais a partir de uma perspectiva fenomenológica. Revista Ciência e Educação, v. 12 n. 2, 2006.

GATTI, B. A. Formação de professores para o ensino fundamental: estudo de currículos das licenciaturas em pedagogia, língua portuguesa, matemática e ciências biológicas. FCC/DPE, São Paulo, SP, 2009.

GERMANO, M. G.; KULESZA, W. A. Popularização do ensino de ciências: uma revisão conceitual. Caderno Brasileiro de Ensino de Física, v. 24, n. 1, p. 7-25, 2007.

KRASILCHIK, M. Prática de ensino de biologia. São Paulo, SP, Edusp, 2005.

LABURÚ, C. E.; ARRUDA, S. M.; NARDI, R. Pluralismo metodológico no ensino de ciências. Revista Ciência e Educação, v. 9, n. 2, 2003.

LORENZETTI, L.; DELIZOICOV, D. Alfabetização Científica no contexto das séries iniciais. Ensaios pesquisa em educação em ciências, v. 3, n. 1, 2001.

LUNARDI, M. L. Implicações das relações interpessoais na aprendizagem. In: TONINI, A. Psicologia das relações educacionais. Gráfica e Editora Pallotti, 1 ed. Santa Maria, RS, 2005.

LOCH, R. E. N. Cartografia Tátil: mapas para deficientes visuais. Portal da Cartografia. Londrina, PR, v. 1, n. 1, 2008.

MACIEL, M. R. Portadores de deficiência: a questão da inclusão. São Paulo em perspectiva. São Paulo, SP, v. 14, n. 2, 2000

MASINI, E. F. S. O perceber e o relacionar-se do deficiente visual; orientando professores especializados. Revista Brasileira de Educação Especial, Santa Maria, RS, 1990.

MUNHÓZ, M. A. Aprendizagem como produção interpessoal. In: TONINI, A. Psicologia das relações educacionais. Gráfica e Editora Pallotti, l ed. Santa Maria, RS, 2005.

NAUJORKS, M. I. Stress e inclusão: indicadores de stress em professores frente a inclusão de alunos com necessidade educacionais especiais. Cadernos, n. 20, 2002. Disponível em: ‘http://coralx.ufsm.br/revce/ ceesp/2002/02/a9.htm .Acesso em: 10 de novembro de 2011.

ORLANDI, E. P. Análise do discurso: princípios e procedimentos. Pontes, 2005. 
PARANÁ, Secretaria Estadual de Educação - Diretrizes Curriculares da Educação Básica: Ciências. 2008.

PATTON, M. Qualitative evaluation methods. Sagepublication. Baverly Hills, 1986.

PEDROCHI, F.; NEVES, M. C. D. Concepções astronômicas de estudantes no ensino superior. Revista Electrónica de Enseñanza de lãs Ciências, v. 4, n. 2, 2005.

PINHEIRO, N. A. M.; SILVEIRA, R. M. C. F.; BAZZO, W. A. B. Ciência, tecnologia e sociedade: a relevância do enfoque cts para o contexto do ensino médio. Revista Ciência e Educação, v. 13, n. 1, 2007.

SANT'ANA, I. M. Educação Inclusiva: concepções de professores e diretores. Psicologia em Estudo, Maringá, v. 10, n. 2, 2005.

SAVIANI, D. O trabalho como principio educativo frente às novas tecnologias. 1994. Disponível em: 〈http:/www.diaadia.pr.gov.br/nre/cornelioprocopio/arquivos/File/Ensinomedioblocos/ Encontro3Otrabalhocomoprincipioeducativo.pdf〉. Acesso em: 21 de outubro de 2011.

TARDIF, M.; RAYMOND, D. Saberes, tempo e aprendizagem do trabalho no magistério. Revista Educação e Sociedade, A. 21, n. 73, 2000.

ZANELLA, L. Aprendizagem: uma introdução.In LA ROSA, et al. Psicologia e Educação, EDIPUCRS, 7 ed. Porto Alegre, RS, 2003.

WAISELFISZ, J. Tamanho da turma: faz diferença? Fundescola/MEC, Brasília, DF, 2000.

\section{Correspondência}

Iohanna Elizabeth Beckers - Universidade Federal de Santa Maria, Avenida Roraima, 1000, CEP: 97105900, Camobi, Santa Maria, Rio Grande do Sul, Brasil.

E-mail: iohannabeckers@hotmail.com-jlcpereira@gmail.com - trogello@hotmail.com

Recebido em 14 de dezembro de 2012

Aprovado em 01 de abril de 2013 